\title{
Pleural Adhesion Assessment as a Predictor for Pneumothorax after Endobronchial Valve Treatment
}

\author{
Wouter H. van Geffen ${ }^{a}{ }^{b}$ Karin Klooster ${ }^{b}$ Jorine E. Hartman ${ }^{b}$ \\ Nick H.T. Ten Hacken ${ }^{b}$ Huib A.M. Kerstjens ${ }^{b}$ Rienhart F.E. Wolf ${ }^{b}$ \\ Dirk-Jan Slebos ${ }^{\text {b }}$ \\ a Department of Respiratory Medicine, Medical Center Leeuwarden, Leeuwarden, and ${ }^{\mathrm{b}}$ Department of Pulmonary \\ Diseases, University Medical Center Groningen, University of Groningen, Groningen, The Netherlands
}

\section{Keywords}

Pneumothorax · Lung volume reduction · Chronic obstructive pulmonary disease - Bronchoscopy ·

Emphysema $\cdot$ Valves $\cdot$ Hyperinflation

\begin{abstract}
Background: Pneumothorax after bronchoscopic lung volume reduction using one-way endobronchial valves (EBVs) in patients with advanced emphysema occurs in approximately $20 \%$ of patients. It is not well known which factors predict the development of pneumothorax. Objective: To assess whether pleural adhesions on pretreatment high-resolution computed tomography (HRCT) scans are associated with pneumothorax occurrence after EBV treatment. Methods: HRCT scan analyses were performed on all patients who received EBV treatment in a randomized controlled trial. Three blinded readers scored adhesions by number and by measuring the longest axis of each pleural adhesion in the treated lung. The Pleural Adhesion Score (PAS) was calculated by adding 1 point for each small pleural lesion ( $<1 \mathrm{~mm})$, 5 points for each medium-sized lesion (1-5 $\mathrm{mm})$, and 10 points for each large lesion (>5 mm). Results: The HRCT scans of 64 treated patients were assessed, of whom 14 de-
\end{abstract}

\section{KARGER}

E-Mail karger@karger.com www.karger.com/res
(C) 2017 The Author(s)

Published by S. Karger AG, Basel

Karger

Open access

This article is licensed under the Creative Commons AttributionNonCommercial-NoDerivatives 4.0 International License (CC BYNC-ND) (http://www.karger.com/Services/OpenAccessLicense). Usage and distribution for commercial purposes as well as any distribution of modified material requires written permission. veloped pneumothorax. Patients who developed pneumothorax had a higher median number of pleural adhesions, 2.7 (IQR 1.9-4) compared to $1.7(1-2.7)$ adhesions in the group without pneumothorax $(p<0.01)$. The PAS in the group with pneumothorax was higher compared to that in the group without: $14.3(12.4-24.1)$ versus $6.7(3.7-11.2)(p<0.01)$. A threshold PAS of $\geq 12$ was associated with a higher risk of pneumothorax (OR 13.0, 95\% Cl 3.1-54.9). A score <12 did not rule out the occurrence of pneumothorax. Conclusion: A higher number of pleural adhesions on HRCT with a subsequent higher PAS in the treated lung is associated with a higher occurrence of pneumothorax after EBV treatment.

(c) 2017 The Author(s)

Published by S. Karger AG, Basel

\section{Introduction}

Bronchoscopic lung volume reduction is a rapidly developing treatment option for emphysema patients with severe hyperinflation [1-6]. Following careful selection of the right patients, lung volume reduction may lead to clinically relevant improvements in lung function, quality of life, and exercise performance [7-13]. Of the available techniques, treatment with endobronchial valves

Wouter H. van Geffen, MD

Department of Respiratory Medicine, Medical Center Leeuwarden Henri Dunantweg 2

NL-8934 AD Leeuwarden (The Netherlands)

E-Mail wouter.van.geffen@znb.nl 


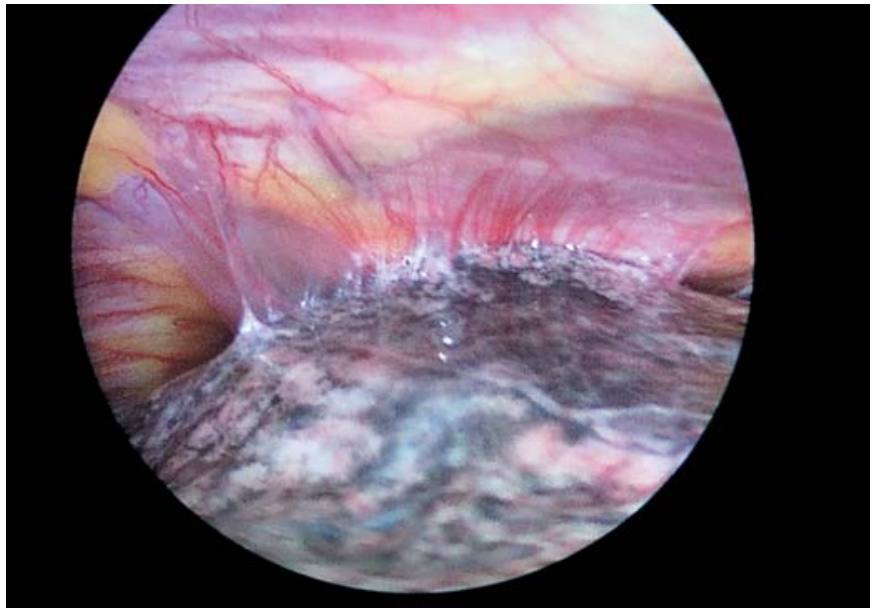

Fig. 1. Example image of a pleural adhesion observed during video-assisted thoracoscopy.

(EBVs) in patients without interlobar collateral ventilation shows the best results [14-18]. However, pneumothorax after EBV treatment is a common adverse event, occurring in about $20 \%$ of patients [19]. Its severity varies, from just an asymptomatic radiologic abnormality, pneumothorax ex vacuo, to life-threatening tension pneumothorax [20, 21]. A reliable risk assessment for pneumothorax is therefore an important unmet need in this new treatment area. Identifying which patients are at higher risk may help informing them better about their individual risks and lead to longer planned observation time in the hospital after treatment.

It is not well known what causes the development of pneumothorax after EBV treatment [19]. A possible explanation is that the pneumothorax is caused by preexisting adhesions between the treated lung and the parietal pleura (see Fig. 1 for a thoracoscopic view). Large volume shifts after successful EBV treatment and subsequent repositioning of the lung could subsequently rupture the visceral pleura. Whether this explanation is valid remains unknown, since pleural adhesions have not been systemically assessed from this point of view. Indeed, an earlier study showed that larger changes in volume after treatment were associated with a higher risk of pneumothorax, an observation that fits the hypothesis that pleural adhesions present a risk [19]. However, that study did not assess whether a larger volume of the target lobe is a risk factor. Other possible mechanisms involve visceral pleural rupture in target and nontarget lobe surfaces, rupture of the bulla, or a mechanism unrelated to pleural surface rupture but due to a mismatch between

Pleural Adhesion Assessment as a Predictor for Pneumothorax after EBV Treatment the lung and the thoracic cage, causing pneumothorax ex vacuo. Pneumothorax related to procedure and postprocedure management might occur due to high mechanical ventilation pressures, Chartis measurements, and heavy coughing. Furthermore, specific emphysema phenotype, heterogeneity of emphysema, and emphysema severity might influence the pneumothorax risk after valve therapy.

The objective of this study was to assess whether pleural adhesions on pretreatment high-resolution computed tomography (HRCT) scans are associated with pneumothorax after EBV treatment. We hypothesized that pleural adhesions are associated with the occurrence of pneumothorax in lungs treated with EBV. In addition, we hypothesized that larger volumes of the target lobes are also associated with the occurrence of pneumothorax.

\section{Materials and Methods}

\section{Study Design}

The pretreatment HRCT scans of all patients who had received EBV treatment in the STELVIO trial [14] were analyzed. In this trial, 64 patients with severe emphysema and hyperinflation were treated with valves in the absence of collateral flow between the target lobe and the ipsilateral nontarget lobe between June 2011 and November 2014. The inclusion criteria included a postbronchodilator forced expiratory volume in $1 \mathrm{~s}\left(\mathrm{FEV}_{1}\right)<60 \%$ of predicted, a total lung capacity (TLC) $>100 \%$ of predicted, and a residual volume (RV) $>150 \%$ of predicted. Furthermore, the HRCT scan needed to demonstrate a target lobe with a (near-)complete interlobar fissure. The main exclusion criterion was evidence of collateral ventilation in the target lobe during Chartis measurement. Patients were randomized to receive immediate EBV treatment or standard care. The standard care group was treated with EBV after 6 months of follow-up. In the current analyses, the data of both groups were combined. Details of the trial, including its design, ethics, informed consent, and inclusion/exclusion criteria have been published previously [14]. All patients provided informed consent and confidentiality was maintained.

All patients were observed after treatment in the hospital for at least 1 day. Chest X-rays were performed directly after treatment, before discharge, and when indicated in case of symptoms to assess the presence of pneumothorax. The occurrence of pneumothorax was registered until 1 year after treatment for all patients.

Scoring of the Occurrence of Pleural Adhesions

To identify pleural lesions, the baseline chest HRCT scan was assessed by three blinded readers (two pulmonologists and a specialized chest radiologist). The readers were not informed about the later occurrence of pneumothorax during reading. They individually and independently assessed the number, location, and size of pleural adhesions in the treated lung. They were instructed to report only lesions with pleural involvement; peripheral lung lesions without pleural involvement were therefore not reported. 
Fig. 2. Examples of pleural adhesions. Top row: Three different-sized pleural adhesions. Bottom row: red indicates the size of each adhesion. The lesion on the left was measured as $<1 \mathrm{~mm}$, resulting in a PAS of 1 point, the middle one was measured as $1-5 \mathrm{~mm}$, resulting in 5 points, and the lesion on the right was measured as $>5 \mathrm{~mm}$, resulting in 10 points.
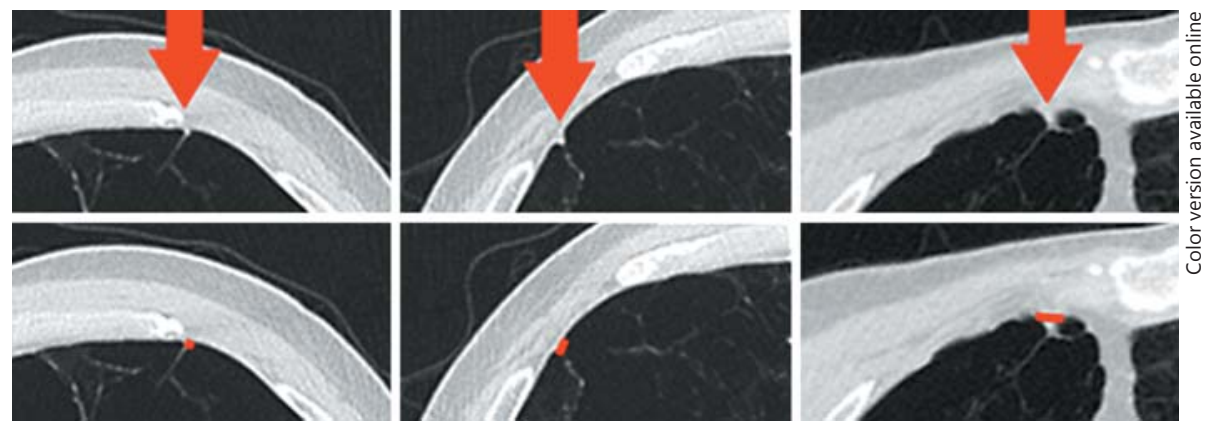

Table 1. Baseline characteristics of the patients

$\begin{array}{lll}\begin{array}{l}\text { All patients } \\ (n=64)\end{array} & \text { Without } & \text { With } \\ & \begin{array}{l}\text { pneumothorax } \\ (n=50)\end{array} & \begin{array}{l}\text { pneumothorax } \\ (n=14)\end{array}\end{array}$

$p$ value $^{\mathrm{a}}$ $\begin{array}{ll}\text { pneumothorax } & \text { pneumothorax } \\ (n=50) & (n=14)\end{array}$

Demographic characteristics

Female sex

Age, years

Body mass index ${ }^{b}$

Number of pack-years

$\begin{array}{ll}67 \% & 62 \% \\ 59(53-65) & 59(53-64) \\ 24(22-26) & 24(22-26) \\ 35(23-45) & 35(22-45)\end{array}$

$\begin{array}{ll}86 \% & 0.10 \\ 62(52-68) & 0.39 \\ 23(22-25) & 0.71 \\ 33(24-45) & 0.66\end{array}$

Lung function

Forced expiratory volume in $1 \mathrm{~s}$

Value, L

Percent of predicted value

Forced vital capacity

Value, L

Percent of predicted value

Residual volume

Value, L

Percent of predicted value

Total lung capacity

Value, L

Percent of predicted value

Residual volume/total lung capacity

Ratio, \%

$\begin{array}{cccc}0.79(0.61-0.94) & 0.88(0.64-1.01) & 0.71(0.53-0.83) & 0.05 \\ 28(24-36) & 28(25-37) & 27(23-32) & 0.16 \\ & & & \\ 2.62(2.00-3.21) & 2.65(2.01-3.41) & 2.53(1.85-3.03) & 0.29 \\ 79(65-93) & 79(65-92) & 76(65-94) & 0.81 \\ & & & \\ 4.34(3.82-5.04) & 4.34(3.81-4.89) & 4.32(3.85-5.29) & 0.69 \\ 214(195-240) & 209(193-232) & 224(200-254) & 0.20 \\ & & & \\ 7.21(6.70-8.48) & 7.25(6.62-8.60) & 7.19(6.80-7.84) & 0.81 \\ 131(124-141) & 130(124-136) & 141(128-144) & 0.61\end{array}$

Arterial blood gas

$131(124-141)$

$130(124-136)$

$141(128-144)$

0.61

$58(53-68)$

$58(51-69)$

$62(56-67)$

0.07

$\mathrm{PaCO}_{2}, \mathrm{kPa}^{\mathrm{c}}$

$\mathrm{PaO}_{2}, \mathrm{kPa}^{\mathrm{c}}$

Exercise performance

Distance on 6-min walk test, $\mathrm{m}$

Quality of life

St. George's Respiratory Questionnaire total score, points ${ }^{\mathrm{d}}$

Modified Medical Research Council scale, points ${ }^{\mathrm{e}}$

Clinical COPD Questionnaire total score, points ${ }^{\mathrm{f}}$

$5.0(4.7-5.6)$

$9.3(8.0-10.2)$

$5.0(4.7-5.6)$

$9.3(8.0-10.2)$

$5.2(4.7-6.1)$

$9.0(7.5-10.7)$

0.38

0.96

$356(300-427) \quad 383(305-431) \quad 325(275-407) \quad 0.13$

Values are presented as median (IQR) unless indicated otherwise. COPD, chronic obstructive pulmonary disease; $\mathrm{PaCO}_{2}$, partial pressure of carbon dioxide; $\mathrm{PaO}_{2}$, partial pressure of oxygen. ${ }^{a}$ Between-group difference (nonparametric). ${ }^{\mathrm{b}}$ Weight in kg divided by the square of the height in $\mathrm{m}^{2}$. ${ }^{\mathrm{c}}$ Measurements were performed while the patient was breathing ambient air. ${ }^{\mathrm{d}}$ Scores range from 0 to 100 , with higher scores indicating worse quality of life. ${ }^{\text {e }}$ Scores range from 0 to 4 , with higher scores indicating a greater severity of dyspnea. ${ }^{\mathrm{f}}$ Scores range from 0 to 10 , with higher scores indicating worse function. van Geffen/Klooster/Hartman/ Ten Hacken/Kerstjens/Wolf/Slebos 


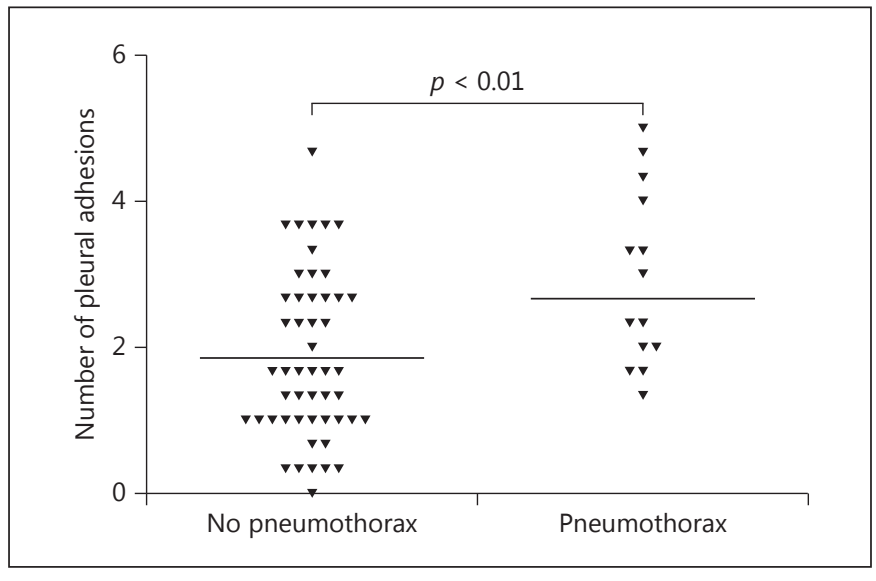

Fig. 3. Total number of pleural adhesions in the target lung by group based on the occurrence of pneumothorax after one-way endobronchial valve treatment. Each triangle represents the mean of the observed number of pleural adhesions in a single participant by three assessors. The Mann-Whitney U test was used to assess the difference between the groups. The horizontal line represents the median.

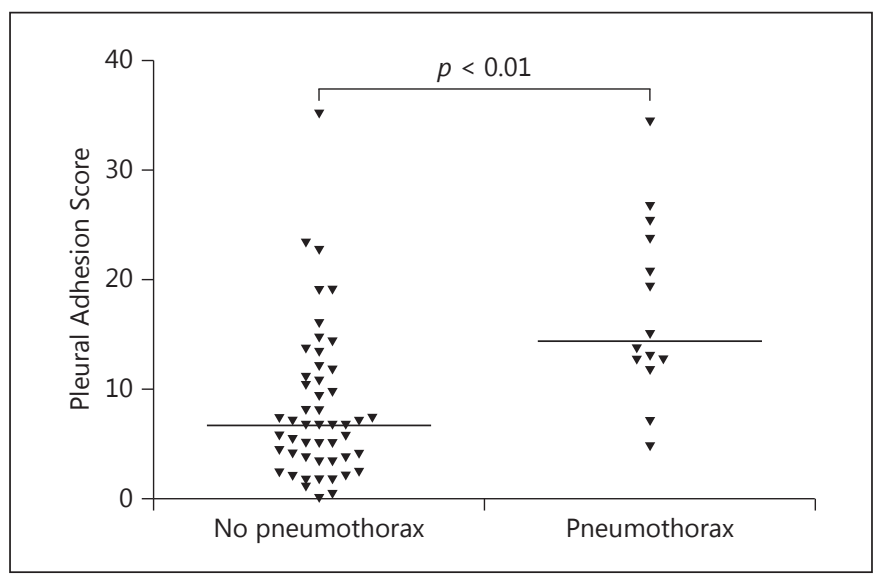

Fig. 4. Pleural Adhesion Score in the target lung based on the occurrence of pneumothorax after one-way endobronchial valve treatment. Each triangle represents the mean Pleural Adhesion Score of the three assessors. The Mann-Whitney U test was used to assess the difference between the groups. The horizontal line represents the median score.

\section{Pleural Adhesion Score}

It was hypothesized that larger lesions produce more traction on the pleura and therefore increase the pneumothorax risk. Therefore, the size of a pleural adhesion was measured and categorized into an arbitrary score: 1 point for each small pleural lesion $(<1 \mathrm{~mm}), 5$ points for each medium-sized lesion $(1-5 \mathrm{~mm})$, and 10 points for each large lesion ( $>5 \mathrm{~mm}$ ) (Fig. 2 ). This system was developed before the assessment of the pleural lesions by the readers

Pleural Adhesion Assessment as a Predictor for Pneumothorax after EBV Treatment was completed. Afterwards, all scores in an individual patient were cumulated into the so-called Pleural Adhesion Score (PAS). The PAS was also expressed per treated and untreated lobes. Finally, for each patient an average PAS of all three assessors was calculated.

Volume Measurements

Quantitative volume measurements of the treated and untreated lobes were performed on the baseline inspiratory HRCT using the Thirona Lung Quantification CT software version 15.01 (Thirona, Nijmegen, The Netherlands) [14, 22, 23].

\section{Analyses}

To assess differences between the groups of patients with and without pneumothorax, independent-sample Mann-Whitney U tests were performed. To derive a threshold for the PAS, a receiver operating characteristic (ROC) curve with a sensitivity and specificity of at least 0.8 was used. The ORs were calculated using logistic regression. Variation between the readers was analyzed with the intraclass correlation coefficient. A $p$ value $<0.05$ was considered significant. SPSS version 22 (IBM, USA) was used for the statistical analyses.

\section{Results}

The HRCTs of the 64 patients were all assessed by three blinded readers. Fourteen patients (22\%) developed pneumothorax after EBV treatment and 50 patients (78\%) did not. Ten patients required chest tube drainage, 4 patients with pneumothorax ex vacuo did not. The baseline characteristics of both groups are reported in $\mathrm{Ta}$ ble 1 . No statistically significant differences were observed between the two groups; nevertheless, the pneumothorax group tended to a slightly lower absolute $\mathrm{FEV}_{1}$ $(p=0.05)$ and more hyperinflation (RV/TLC ratio) ( $p=$ 0.07 ). Due to the low number of pneumothoraxes no separate analysis was performed on subgroups with different types of pneumothorax.

\section{Pleural Lesions}

Participants with a higher number of pleural adhesions more often developed pneumothorax: patients who developed pneumothorax had a median number of 2.7 (IQR 1.9-4) adhesions compared to 1.7 (1-2.7) adhesions in patients without pneumothorax $(p<0.01)$ (Fig. 3; Table 2). The Pearson correlation between small lesions and pneumothorax was $r=0.22$, and large lesions had a correlation with pneumothorax of $r=0.29$.

No significant difference between the groups was found when separately assessing the number of pleural adhesions in the treated lobe. The patients who developed pneumothorax showed more adhesions in the untreated 
Table 2. Results of the analysis

\begin{tabular}{|c|c|c|c|c|}
\hline Characteristics & $\begin{array}{l}\text { All patients } \\
(n=64)\end{array}$ & $\begin{array}{l}\text { Without } \\
\text { pneumothorax } \\
(n=50)\end{array}$ & $\begin{array}{l}\text { With } \\
\text { pneumothorax } \\
(n=14)\end{array}$ & $p$ value $^{\mathrm{a}}$ \\
\hline \multicolumn{5}{|l|}{ Pleural adhesions ${ }^{\mathrm{b}}$} \\
\hline Treated lobe & $1.3(0.7-2)$ & $1.0(0.3-2)$ & $1.5(1.0-2.7)$ & 0.06 \\
\hline Untreated lobe & $0.7(0.3-1.3)$ & $0.5(0-1.3)$ & $1(0.6-1.5)$ & 0.04 \\
\hline Total treated lung & $1.8(1-3)$ & $1.7(1-2.7)$ & $2.7(1.9-4.0)$ & $<0.01$ \\
\hline \multicolumn{5}{|l|}{ Pleural Adhesion Score } \\
\hline Treated lobe & $5.3(2-10)$ & $4.8(1.5-7.9)$ & $10(8.3-19.5)$ & $<0.01$ \\
\hline Untreated lobe & $1.7(0.3-5.7)$ & $1.7(0-5.7)$ & $4(1.4-6.8)$ & 0.04 \\
\hline Total treated lung & $7.3(4.3-13.7)$ & $6.7(3.7-11.2)$ & $14.3(12.4-24.1)$ & $<0.01$ \\
\hline \multicolumn{5}{|l|}{ Lobar volumes } \\
\hline Treated lobe volume, $\mathrm{mL}$ & $1,773(1,446-2,145)$ & $1,790(1,465-2,150)$ & $1,720(1,378-2,093)$ & 0.66 \\
\hline $\begin{array}{l}\text { Treated lobe volume, percentage of } \\
\text { total treated lung volume }\end{array}$ & $53(47-61)$ & $53(48-62)$ & $53(48-60)$ & 0.88 \\
\hline
\end{tabular}

Values are presented as median (IQR). ${ }^{a}$ Between-group difference (nonparametric). ${ }^{b}$ Mean number observed by the three readers.

lobe than those who did not develop pneumothorax $1(0.6-1.5)$ and $0.5(0-1.3)$, respectively, $p=0.04$.

\section{Pleural Adhesion Score}

The PAS (median and IQR) in the group with pneumothorax was 14.3 (12.4-24.1) compared to 6.7 (3.7$11.2)$ in the group without $(p<0.01)$ (Table 2; Fig. 4$)$. Every extra point on the PAS was associated with a higher pneumothorax risk - an OR of 1.2 (95\% CI 1.1-1.3, $p<$ 0.01 ) per point. From the ROC curve, an area under the curve of 0.83 was calculated (Fig. 5). From the ROC curve a threshold PAS of $\geq 12$ was derived to achieve a sensitivity and specificity of both 0.8 . A score above this threshold showed a markedly higher risk for pneumothorax (OR 13.0, 95\% CI 3.1-54.9). However, 3 patients with a PAS $<12$ developed pneumothorax after treatment. The negative predictive value of the PAS was $93 \%$, the positive predictive value was $48 \%$. Analysis of the individual PAS of the three readers showed an intraclass correlation coefficient of 0.46 .

\section{Volumes}

No difference in volumes of the individual target lobes or target lobe to total lung ratio was detected between the groups (Table 2). In 51 patients it was possible to measure the change in total lung volume after EBV treatment with CT volume measurements. Eight of these developed pneumothorax. No difference between the groups in target lobar volume reduction was detected; however, this

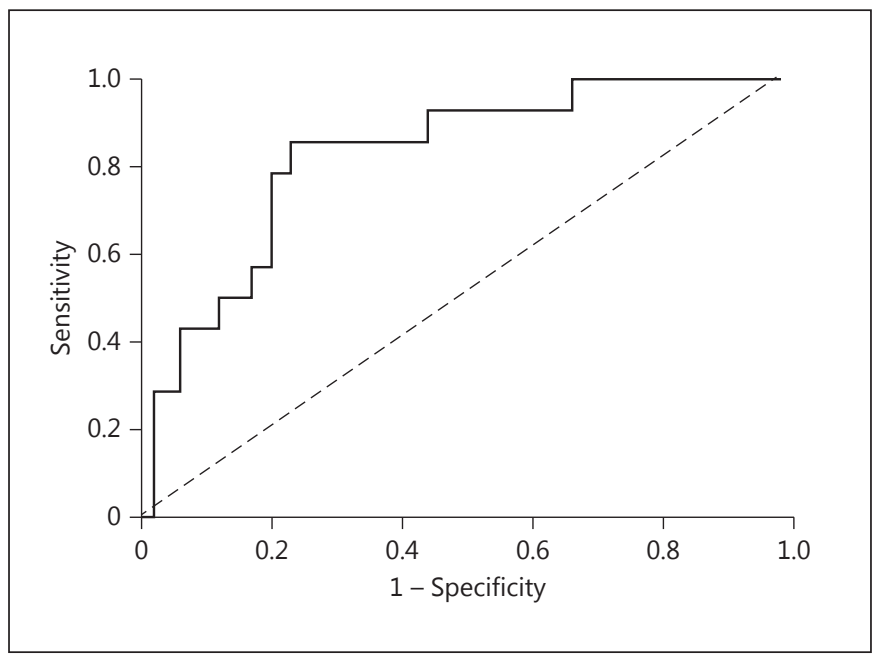

Fig. 5. Receiver operating characteristic curve of the Pleural Adhesion Score for pneumothorax. Solid line, Pleural Adhesion Score; dashed line, reference line. The area under the curve is 0.83 .

finding should be interpreted with care since we could not measure in 6 of the pneumothorax patients.

\section{Location}

Thirty-six patients were treated in the upper lobes, of whom 9 developed pneumothorax (25\%), whereas 5 out of the 28 lower-lobe-treated patients developed pneumothorax $(18 \%)(p=0.43)$. 


\section{Discussion}

Our analysis of the presence of pleural adhesions on the pretreatment inspiratory HRCT scans of all patients treated with one-way EBVs in the STELVIO trial [14] showed that a higher number and larger size of pleural adhesions in the treated lung was associated with a higher occurrence of pneumothorax after treatment.

EBV treatment has been shown to be a very effective treatment for patients with severe emphysema without collateral ventilation [14]. However, both the STELVIO trial [14] and the BeLieVeR-HIFi [16] trial demonstrated that about $20 \%$ of treated patients develop pneumothorax early after treatment. Although pneumothorax after EBV treatment is nowadays considered to be part of the treatment, for these patients, the occurrence of pneumothorax can be a serious complication associated with higher morbidity, prolonged hospital admissions, chest tube insertions, additional bronchoscopies, treatment failure, and rarely even death $[14,16,19,20]$. Better patient selection and prediction of pneumothorax risk is therefore of great importance. Our results showed that pleural adhesions assessment may identify patients at risk. The design of this study allows only preliminary conclusions and as a next step, the PAS should be prospectively studied, perhaps combined with video-assisted thoracoscopy results and multivariate analysis. In our view, a high PAS and therefore a higher pneumothorax risk could lead to a number of measures to be taken. First, a prolonged observation period in the hospital could be considered, although it remains difficult to predict when it is safe to discharge patients. Second, a more intensive observation with repeated chest X-rays could be considered. Third, bed rest and cough reduction might be attractive, as Herzog et al. [24] demonstrated that such a regimen reduces the occurrence of early pneumothorax from 25 to $5 \%$. Even more speculative is the performance of prophylactic interpleural drainage in patients at high risk for lifethreatening pneumothoraxes or surgical removal of the adhesions prior to treatment. Finally, the risk of a higher PAS could be discussed between the physician and the patient who is a candidate for bronchoscopic volume reduction treatment.

This study observed a higher PAS in the treated compared with the untreated lobe. Both study design and sample size, however, did not allow reliable analysis of associations between the severity of the pneumothorax and the distribution of the pleural adhesions. However, one would expect that a more severe pneumothorax with a larger air leak is caused by lesions in the untreated lobe.

Pleural Adhesion Assessment as a Predictor for Pneumothorax after EBV Treatment
Next to the pleural adhesions, we hypothesized that the volume of the treated lobe at baseline on HRCT could correlate with pneumothorax occurrence. In the analysis by Gompelmann et al. [19], change in volume after treatment of the target was related to pneumothorax risk. The present study could not assess the change in lung volume after the procedure in relation with pneumothorax occurrence. From a post hoc view one might argue that this change in volume is more associated with pneumothorax occurrence; however, we aimed to predict the risk before starting the treatment. At baseline, in our study the median target lobar volume was not significantly different between the groups, an observation that persisted when target lobar volume was corrected for total lung volume. Furthermore, we observed a trend that patients in the group who developed pneumothorax were more often treated in the upper lobes and had a lower $\mathrm{FEV}_{1}$ and more hyperinflation. This could reflect more destruction and perhaps additional vulnerability of the tissue.

Previous data about systemic scoring of pleural adhesions are not available, perhaps because it was thought not to have clinical consequences. Only one paper assessing pleural adhesions as a minor endpoint amongst others was recently published [25]. The authors found adhesions to be slightly protective against pneumothorax. However, these adhesions were not scored systematically and were analyzed by a single reader only. Also since pleural adhesions had not been systematically examined before as a risk factor for pneumothorax, we had to develop a new scoring system. Taking into account the results of our study, the PAS appeared to be a tool to estimate this risk, with an area under the curve of 0.83 . However, the PAS was the average score of three independent readers, who demonstrated only moderate agreement. On the other hand, this interobserver agreement is comparable to the interobserver agreements of other radiological scores, for instance in interstitial lung diseases and fissure assessment [26-28]. Further optimization in quantifying pleural adhesions is clearly needed in such a way that only one reader is needed to produce reliable measurements, or even better to develop quantitative CT analysis software to measure this.

Another interesting opportunity is to assess the pleura in more detail, especially in relation with the surrounding tissue, e.g., by targeted ultrasound. Cassanelli et al. [29] already showed that ultrasound is able to detect pleural adhesions. Future studies might investigate whether patients with more peripheral destruction in panlobular or paraseptal emphysema and adjacent pleural adhesions are at higher risk of developing pneumothorax than pa-

Respiration 2017;94:224-231 229 
tients with a more centrilobular emphysema. Another related question that could be raised is whether the completeness and speed of the development of atelectasis of the treated lobe is associated with the occurrence of pneumothorax, or whether the presence of adhesions per se is more important.

\section{Conclusion}

Our study showed that more extensive pleural adhesions are associated with higher risk of pneumothorax after treatment with EBV. These data, if prospectively validated, have the potential of significantly influencing treatment decisions and algorithms.

\section{Acknowledgments}

This study was supported by a grant (171101008, to the University Medical Center Groningen) from the Netherlands Organization for Health Research and Development (ZonMw) and by innovation funding from the University Medical Center Groningen.

\section{Statement of Ethics}

All patients provided informed consent and confidentiality was maintained. The trial was approved by the ethics committee of the University Medical Center Groningen.

\section{Financial Disclosure and Conflicts of Interest}

W.H. van Geffen received a European Respiratory Society Fellowship STRTF 2016 and reports a grant from Novartis to the institution for an investigator-initiated trial, both outside of the submitted work. K. Klooster reports travel grants and personal fees from PulmonX and PneumRx/BTG. H.A.M. Kerstjens had fees paid to his institution based on advisory board participation, lectures, and per patient recruited in trials from AstraZeneca/Almirall, Boehringer Ingelheim, Chiesi, GSK, Novartis, Pfizer, Takeda, TEVA, PneumRx/BTG, Holaira, PulmonX, Boston Scientific, and Olympus. D.-J. Slebos reports grants, personal fees, nonfinancial support, and other from PneumRx/BTG, USA, grants, personal fees, nonfinancial support, and other from Boston Scientific, Europe/USA, grants and nonfinancial support from Aeris Therapeutics, USA, grants, personal fees, nonfinancial support, and other from Holaira, Inc., USA, personal fees from Olympus Europe, Germany, as well as grants, personal fees, nonfinancial support, and other from PulmonX, USA. J.E. Hartman, N.H.T. Ten Hacken, and R.F.E. Wolf report no conflicts of interest.

\section{References}

$\checkmark 1$ Herth FJ, Slebos DJ, Rabe KF, Shah PL: Endoscopic lung volume reduction: an expert panel recommendation. Respiration 2016;91: 241-250.

2 Koegelenberg CF, Slebos DJ, Shah PL, Theron J, Dheda K, Allwood BW, Herth FJ: Time for the global rollout of endoscopic lung volume reduction. Respiration 2015;90:430-440.

-3 Sciurba FC, Ernst A, Herth FJ, Strange C, Criner GJ, Marquette CH, Kovitz KL, Chiacchierini RP, Goldin J, McLennan G: A randomized study of endobronchial valves for advanced emphysema. N Engl J Med 2010; 363:1233-1244.

4 Shah PL, Herth FJ, van Geffen WH, Deslee G, Slebos DJ: Lung volume reduction for emphysema. Lancet Respir Med 2017;5:147-156.

5 Bandyopadhyay S, Henne E, Gupta A, Barry R, Snell G, Strange C, Herth FJ: Segmental approach to lung volume reduction therapy for emphysema patients. Respiration 2015;89: 76-81.

-6 Valipour A, Slebos DJ, Herth F, Darwiche K, Wagner M, Ficker JH, Petermann C, Hubner RH, Stanzel F, Eberhardt R; Impact Study Team: Endobronchial valve therapy in patients with homogeneous emphysema. Results from the IMPACT Study. Am J Respir Crit Care Med 2016;194:1073-1082.

7 Mineshita M, Slebos DJ: Bronchoscopic interventions for chronic obstructive pulmonary disease. Respirology 2014;19:1126-1137.
8 Klooster K, Ten Hacken NH, Franz I, Kerstjens HA, van Rikxoort EM, Slebos DJ: Lung volume reduction coil treatment in chronic obstructive pulmonary disease patients with homogeneous emphysema: a prospective feasibility trial. Respiration 2014;88:116-125.

>9 Kontogianni K, Gerovasili V, Gompelmann D, Schuhmann M, Heussel CP, Herth FJ, Eberhardt R: Effectiveness of endobronchial coil treatment for lung volume reduction in patients with severe heterogeneous emphysema and bilateral incomplete fissures: a sixmonth follow-up. Respiration 2014;88:52-60

10 Slebos DJ, Shah PL: Go with the flow: the importance of the assessment of collateral ventilation in endobronchial valve treatment. Respiration 2016;91:269-270.

11 Puente-Maestu L, Palange P, Casaburi R, Laveneziana P, Maltais F, Neder JA, O’Donnell DE, Onorati P, Porszasz J, Rabinovich R, Rossiter HB, Singh S, Troosters T, Ward S: Use of exercise testing in the evaluation of interventional efficacy: an official ERS statement. Eur Respir J 2016;47:429-460.

12 Gompelmann D, Eberhardt R, Ernst A, Hopkins P, Egan J, Stanzel F, Valipour A, Wagner M, Witt C, Baker KM, Gotfried MH, Kesten S, Snell G, Herth FJ: The localized inflammatory response to bronchoscopic thermal vapor ablation. Respiration 2013;86:324-331.
13 Herth FJ, Gompelmann D, Stanzel F, Bonnet R, Behr J, Schmidt B, Magnussen H, Ernst A, Eberhardt R: Treatment of advanced emphysema with emphysematous lung sealant $\left(\right.$ AeriSeal ${ }^{\circledR}$ ). Respiration 2011;82:36-45.

14 Klooster K, Ten Hacken NH, Hartman JE, Kerstjens HA, van Rikxoort EM, Slebos DJ: Endobronchial valves for emphysema without interlobar collateral ventilation. N Engl J Med 2015;373:2325-2335.

15 Slebos DJ, Hartman JE, Klooster K, Blaas S, Deslee G, Gesierich W, Hetzel J, Hetzel M, McNulty W, Kemp SV, Kessler R, Leroy S, Stanzel F, Witt C, Zoumot Z, Herth FJ, Shah PL: Bronchoscopic coil treatment for patients with severe emphysema: a meta-analysis. Respiration 2015;90:136-145.

16 Davey C, Zoumot Z, Jordan S, McNulty WH, Carr DH, Hind MD, Hansell DM, Rubens MB, Banya W, Polkey MI, Shah PL, Hopkinson NS: Bronchoscopic lung volume reduction with endobronchial valves for patients with heterogeneous emphysema and intact interlobar fissures (the BeLieVeR-HIFi study): a randomised controlled trial. Lancet 2015;386:1066-1073.

17 van Geffen WH, Slebos DJ, Kerstjens HA: Hyperinflation in COPD exacerbations. Lancet Respir Med 2015;3:e43-e44.

18 van Geffen WH, Slebos DJ: Autobullectomy in patients with COPD. Respiration 2015;89:88. 
19 Gompelmann D, Herth FJ, Slebos DJ, Valipour A, Ernst A, Criner GJ, Eberhardt R: Pneumothorax following endobronchial valve therapy and its impact on clinical outcomes in severe emphysema. Respiration 2014;87:485-491.

20 Valipour A, Slebos DJ, de Oliveira HG, Eberhardt R, Freitag L, Criner GJ, Herth FJ: Expert statement: pneumothorax associated with endoscopic valve therapy for emphysema - potential mechanisms, treatment algorithm, and case examples. Respiration 2014;87:513-521.

-21 Cantey EP, Walter JM, Corbridge T, Barsuk $\mathrm{JH}$ : Complications of thoracentesis: incidence, risk factors, and strategies for prevention. Curr Opin Pulm Med 2016;22:378-385.

22 van Rikxoort EM, van Ginneken B: Automated segmentation of pulmonary structures in thoracic computed tomography scans: a review. Phys Med Biol 2013;58:R187-R220.
23 van Rikxoort EM, de Hoop B, Viergever MA, Prokop M, van Ginneken B: Automatic lung segmentation from thoracic computed tomography scans using a hybrid approach with error detection. Med Phys 2009;36:29342947.

24 Herzog D, Poellinger A, Doellinger F, Schuermann D, Temmesfeld-Wollbrueck B, Froeling V, Schreiter NF, Neumann K, Hippenstiel S, Suttorp N, Hubner RH: Modifying post-operative medical care after EBV implant may reduce pneumothorax incidence. PLoS One 2015;10:e0128097.

25 Gompelmann D, Benjamin N, Kontogianni K, Herth F, Heussel CP, Hoffmann H, Eberhardt R: Clinical and radiological outcome following pneumothorax after endoscopic lung volume reduction with valves. Int J Chron Obstruct Pulmon Dis 2016;11:30933099.

26 Walsh SL, Calandriello L, Sverzellati N, Wells AU, Hansell DM: Interobserver agreement for the ATS/ERS/JRS/ALAT criteria for a UIP pattern on CT. Thorax 2016;71:45-51.
7 Watadani T, Sakai F, Johkoh T, Noma S, Akira M, Fujimoto K, Bankier AA, Lee KS, Muller NL, Song JW, Park JS, Lynch DA, Hansell DM, Remy-Jardin M, Franquet T, Sugiyama $\mathrm{Y}$ : Interobserver variability in the CT assessment of honeycombing in the lungs. Radiology 2013;266:936-944.

28 Koenigkam-Santos M, Puderbach M, Gompelmann D, Eberhardt R, Herth F, Kauczor $\mathrm{HU}$, Heussel CP: Incomplete fissures in severe emphysematous patients evaluated with MDCT: incidence and interobserver agreement among radiologists and pneumologists. Eur J Radiol 2012;81:4161-4166.

29 Cassanelli N, Caroli G, Dolci G, Dell'Amore A, Luciano G, Bini A, Stella F: Accuracy of transthoracic ultrasound for the detection of pleural adhesions. Eur J Cardiothorac Surg 2012;42:813-818; discussion 818.
Pleural Adhesion Assessment as a Predictor for Pneumothorax after EBV Treatment
Respiration 2017;94:224-231 DOI: $10.1159 / 000477258$ 